\title{
Oral PTCTS (Particulated Transialidase) Removes Serum Microparticles and Decreases Inflammation in Atherosclerotic Plaques of Rabbits
}

\author{
Shérrira M. Garavelo'ㅗ, Jaqueline J. Pereira', Nilsa S. Y. Wadt', Marcia M. Reis ${ }^{1}$, \\ Renata N. Ikegami ${ }^{1}$, Joyce T. Kawakami' ${ }^{1}$, Abdelali Agouni ${ }^{2,3}$, Suely A. P. Palomino1, \\ Dulcinéia Abdalla', Maria de Lourdes Higuchi' ${ }^{4}$ \\ ${ }^{1}$ Heart Institute (InCor), University of Sao Paulo Clinics Hospital, Sao Paulo, Brazil \\ ${ }^{2}$ Faculty of Health and Medical Sciences (FHMS), University of Surrey, Guildford, UK \\ ${ }^{3}$ College of Pharmacy, Qatar University, Doha, Qatar \\ ${ }^{4}$ Department of Clinical and Toxicological Analysis, Faculty of Pharmaceutical Sciences, University of Sao Paulo, \\ Sao Paulo, Brazil \\ Email:anplourdes@incor.usp.br
}

Received 21 August 2015; accepted 6 November 2015; published 9 November 2015

Copyright (C) 2015 by authors and Scientific Research Publishing Inc.

This work is licensed under the Creative Commons Attribution International License (CC BY). http://creativecommons.org/licenses/by/4.0/

(c) (i) Open Access

\section{Abstract}

Background: Previous studies showed that atherosclerotic plaque vulnerability was related with microparticles (MPs)-vesicles larger than $100 \mathrm{~nm}$, which released MMP9 collagenase. In our previous study, intramuscular injection of a new drug (PTCTS) normalized oxidized LDL serum levels and reduced rabbit atherosclerosis. Now, we studied administration of oral PTCTS in order to clarify anti-atherosclerotic mechanism of action, analyzing if the treatment removed MPs containing ox-LDL and Mycoplasma pneumoniae antigens and improved the immune response. Methods: We compared two groups of rabbits. Control group (CG, $n=6$ ) $-1 \%$ cholesterol enriched diet for 12 weeks; Treated group (TG, $n=8)-1 \%$ cholesterol enriched diet for 12 weeks with administration of PTCTS (400 $\mu \mathrm{l} /$ day) during the last 6 weeks of diet. The animals had their blood collected, in three different phases of the protocol before being fed with hypercholesterolemic diet, before being treated with water or PTCTS and at the moment of sacrifice. The serum was submitted to immunofluorescence technique to evaluate the quantity of microparticles marked with antibodies against Mycoplasma pneumoniae and ox-LDL. A fragment of aorta was submitted to immunohisto-

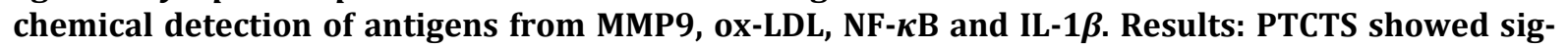

How to cite this paper: Garavelo, S.M., Pereira, J.J., Wadt, N.S.Y., Reis, M.M., Ikegami, R.N., Kawakami, J.T., Agouni, A., Palomino, S.A.P., Abdalla, D. and de Lourdes Higuchi, M. (2015) Oral PTCTS (Particulated Transialidase) Removes Serum Microparticles and Decreases Inflammation in Atherosclerotic Plaques of Rabbits. Advances in Nanoparticles, 4, $107-115$. 
nificant reduction in MMP-9 $(P=0.001)$ and a tendency of reducing $I L-1 \beta(P=0.09)$ in the aortic plaques compared with CG. In the serum, PTCTS was able to remove microparticles containing antigen of ox-LDL $(P=0.004)$ and Mycoplasma pneumoniae $(P<0.001)$. Conclusion: Oral treatment with PTCTS presented more adequate inflammatory response by reducing levels of ox-LDL, IL-1 $\beta$ and mycoplasma, as well as a better stabilization of the atheromatous plaque by reducing levels of MMP-9, avoiding plaque rupture, without causing mortality or toxicity.

\section{Keywords}

Atherosclerosis, Inflammation, PTCTS, Mycoplasma, NF- $\kappa$ B

\section{Introduction}

Atherosclerosis is a chronic inflammatory disease that affects medium and large sized arteries [1] resulting in the formation of fatty and fibrous lesions in the vessel wall. Atherogenesis is marked by inflammatory processes in all its stages, from early endothelial activation by modified lipids to eventual rupture of the atherosclerotic plaque [2] [3].

The first steps in atherosclerosis are the modification of LDL into oxidized LDL (ox-LDL) microparticles, leading to a local inflammation with the release of chemotactic factors and expression of adhesion molecules on the surface of endothelial cells, attraction of monocytes and development of atherosclerotic lesion [4].

The initial inflammatory response in atherosclerosis may be considered an attempt to eliminate potentially harmful ox-LDL microparticles, which has been related to the development of atherosclerosis [5]. Ox-LDL can enhance activation of endothelial cells, and short-term incubation or usage of low concentrations of ox-LDL can also enhance nuclear factor kappa-B (NF- $\kappa \mathrm{B})$ activation in monocytes [6].

As a transcription factor in inflammatory responses, NF- $\kappa$ B is involved in the regulation of inflammatory and immune genes, apoptosis, and cell proliferation [7]. The activation of NF- $\kappa \mathrm{B}$ in endothelial cells during early atherogenesis or in other cells during later stages may occur by many different stimuli [8], including minimally ox-LDL [9] or infectious agents such as chlamydia [10] and mycoplasma [11].

Another activator of the NF- $\kappa \mathrm{B}$ pathway in atherogenesis is IL- $1 \beta$, a pro-inflammatory cytokine released in the lesion site that may affect atherosclerosis by regulating many other NF- $\kappa$ B dependent genes and amplify the inflammatory response [12].

A major factor involved in monocyte-to-macrophage differentiation is macrophage colony-stimulating factor (M-CSF), which is regulated by NF- $\kappa \mathrm{B}$ [13]. For optimal migration of monocyte/macrophages into tissues, degradation of extracellular matrix is a requirement. A crucial enzyme in this process is the matrix metalloproteinase-9 (MMP-9), whose transcription is also regulated by NF- $\kappa \mathrm{B}$ [14]. In addition to mediating macrophage infiltration, MMP-9 also facilitates smooth muscle cell migration [15] that may contribute to the fibrotic cap formation leading to a stabilization of the atheroma plaque. On the other hand, increased levels of MMP-9 are involved in degradation of this fibrous cap and segmental vessel dilatation, favoring plaque rupture [16] [17] and development of aneurysms [18]. In both situations, human studies from our lab found increased amount of microorganisms such as Mycoplasma pneumoniae and Chlamydophila pneumoniae [19], as well as activation of toll like receptors (TLR) 2 and 4 [20]. Antigens from Mycoplasma pneumoniae and oxLDL were found in increased levels in microparticles present in vulnerable plaques [21].

Particulated transialidase (PTCTS) is a compound containing transialidase from Trypanosoma cruzi from recombinant bacteria diluted 10,000× in thermal water and extract of orchid, whose method and production are protected by granted US patents (US7335638B2, US7674832B2 and US7906114B2), with INCI name approved for cosmetics gel that presents anti-aging and anti-oxidative activities [22] produced by Higuchi \& Santos Ciência e Biotecnologia Ltda.

For oral administration, PTCTS is associated with nanoparticles from Allivium sativus, Ginkgo biloba and Zingiber officinalis, whose methods and production are also protected by US patents (US7335638B2, US 7732410 and US7914781) diluted 1:10,000×. In previous study, this compound, injected intramuscularly, had anti-atherosclerotic effect in rabbits [23]. 
Now, we studied if PTCTS' anti-atherosclerotic mechanism of action is linked with removal of microparticles containing ox-LDL and Mycoplasma pneumoniae antigens and improvement in immune response through NF- $\kappa$ B and IL- $1 \beta$ action.

\section{Methods}

\subsection{Experimental Design}

We fed two groups of New Zealand rabbits, from the Central Bioterium of Medical School of University of São Paulo, aging approximately 60 days and weighing $2.2 \pm 0.5 \mathrm{~kg}$ with $1 \%$ cholesterol enhanced diet for 12 weeks in order to induce the atherosclerotic process. The group used as control (CG $n=6,3$ male) was treated with drops of water, while the treated group had oral administration of PTCTS ( $400 \mu \mathrm{L} /$ day $)$ during the last 6 weeks of diet as treatment (TG $n=8,4$ male).

Based on previous pilot studies, with different concentrations of PTCTS compounds, we set a dose of $400 \mu \mathrm{L} /$ day as the best one, and decided to treat the rabbits during the same period it takes to completely develop the atherosclerotic process (6 weeks). Thus, the rabbits were fed with hypercholesterolemic diet for 12 weeks and treated with PTCTS for the last 6 weeks.

The study was developed according to the "Guide for the Care and Use of Laboratory Animals"-US National Institutes of Health (NIH Publication No. 85-23, revised 1996) and approved by the Ethics Committee of the University of Sao Paulo (USP).

\subsection{Sample Collection}

The animals had their blood collected, from the ear marginal vein, in three different phases of the protocol: 1) Before being fed with hypercholesterolemic diet, which values were used as normal control; 2) After being fed with hypercholesterolemic diet and before being treated with water (CG) or PTCTS (TG); 3) At the end of the experiment during the sacrifice, after the rabbits received their treatment.

The animals were sacrificed after 12 weeks of the protocol by previous injection of anesthetics (ketamine 25 $50 \mathrm{mg} / \mathrm{kg}$ associated to xylazin $2-5 \mathrm{mg} / \mathrm{kg}$ via intramuscular) that had their action boosted with intra-cardiac barbituric (Tiopental) and potassium chloride $3 \mathrm{~mL}$. A fragment of aorta was dissected at its root and harvested in $10 \%$ buffered formalin for analysis. Macroscopic and microscopic exams of main organs were performed in order to evaluate toxicity.

\subsection{Immunohistochemistry}

The resected fragments were processed and paraffin-embedded. Serial sections of $5 \mu \mathrm{m}$ were submitted to immunohistochemical detection of MMP-9 antigens (56-2A4-Abcam), ox-LDL (clone 2C7OSF10, prepared and donated by Dr. DulcinéiaAbdalla [24]), NF- $\kappa$ B (polyclonal-Biorbyt), and IL-1 $\beta$ (polyclonal-Cloud-Clone Corp).

Antigen retrieval was performed with $0.15 \%$ Trypsin or buffers (Tris-EDTA $10 \mathrm{mM} \mathrm{pH} 9.0$ or Citrate $10 \mathrm{mM}$ pH 6.0) in a pressure cooker (Pascal, DakoCytomation, USA). The blocking of endogenous peroxidase was performed with $6 \% \mathrm{H}_{2} \mathrm{O}_{2}$, at room temperature (RT). Next, sections were incubated with a Background Suppression Reagent (CAS-Block ${ }^{\mathrm{TM}}$, Invitrogen) for $10 \mathrm{~min}$, RT. Primary antibodies were incubated for $40 \mathrm{~min}$, RT. For the detection of the complex antigen/antibody, Picture Max HRP kit (Invitrogen) was used. Staining procedure was completed using diaminobenzidine chromogen (DAB, Dako Cytomation) and counter-staining with Harris-hematoxylin. The highest point of atherosclerotic plaque was evaluated in $0,5 \mathrm{~mm}$ extension of histological ascendant aorta cross section and evaluated at ImageScope Software (Version 11.2.0.780, Aperio Technologies) by colorimetric differentiation.

\subsection{Immunofluorescence}

We used the immunofluorescence technique to evaluate the quantity of microparticles in the serum marked with primary antibodies against Mycoplasma pneumoniae (Mp)-(clone B748M, Abcam), and ox-LDL (clone 2C7scFv prepared and donated by Dr. Dulcinéia Abdalla).

The serum was incubated with primary antibodies for $1 \mathrm{~h}$ at $25^{\circ} \mathrm{C}$. After this period, we added the secondary 
antibody: Alexa Fluor 488-Invitrogen, for ox-LDL and Alexa Fluor 555-Invitrogen, for Mp and incubated for another hour at $25^{\circ} \mathrm{C}$.

We photographed 4 pictures for all the animals at Evos fluorescence microscope $(\times 20)$. Each picture had the particles counted in two opposite fields of $0.023 \mathrm{~mm}^{2}$ at IrfanView (version 4.35, Irfan Skilijan) software, totaling 8 fields/animal. We calculated the mean of these values for statistical analysis.

\subsection{Statistics}

All data are disposed as mean \pm SD. We used T test to compare the data from CG and TG. For Immunofluorescence we compared the serum from samples 2 and 3 in animals of the same group through paired $T$ test, and used the difference of values from the serum of sample 2 and $3(\Delta T)$ to verify the real difference in number of particles from the groups when correlated with the data obtained from immunohistochemistry by Pearson's Correlation test. All statistical tests were performed at SigmaStat (version 3.5, Systat) software.

\section{Results}

PTCTS did not cause mortality or presented any level of toxicity in the organs evaluated.

\subsection{Immunohistochemistry}

Immunohistochemistry evaluation showed that there was a reduction of some inflammatory markers level in treated group when compared with control group. Treatment with PTCTS lead to a significant reduction of MMP-9 in aorta of rabbits $(P=0.001)$ (Figure 1$)$, and a tendency of the same effect on IL-1 $\beta(P=0.09)$, while the others inflammatory markers presented no difference.

\subsection{Immunofluorescence}

Comparison of the serum collected in phase pre-treatment (2) between the groups demonstrated that both antigens had the same behavior with no significant difference: ox-LDL - CG2: $302.83 \pm 239.58$, TG2: $327.62 \pm$ 89.16, P = 0.81; Mp - CG2: $285.67 \pm 105.86$, TG2: $234.62 \pm 192.41$, P $=0.57$. But when the serum of phase post-treatment (3) was compared, the group treated with PTCTS showed a significant reduction in the quantity of ox-LDL (CG3: $417.17 \pm 220.6$, TG3: $190.87 \pm 55.4, P=0.01$ ) as well as in Mp (CG3: $437.5 \pm$ 198.99, TG3: 132.6298.6, $P=0.003$ ) (Figure 2).

The comparison of $\Delta \mathrm{T}$ of the groups revealed that PTCTS was able to significantly remove particles marked with ox-LDL (CT $\Delta \mathrm{T}: 111.33 \pm 267.25$, TG $\Delta \mathrm{T}:-136.75 \pm 111.12, P=0.004)$ and $\mathrm{Mp}(\mathrm{CG} \Delta \mathrm{T}: 151.83 \pm 112.45$, TG $\Delta$ T: $-102 \pm 100.8, P<0.001)$.

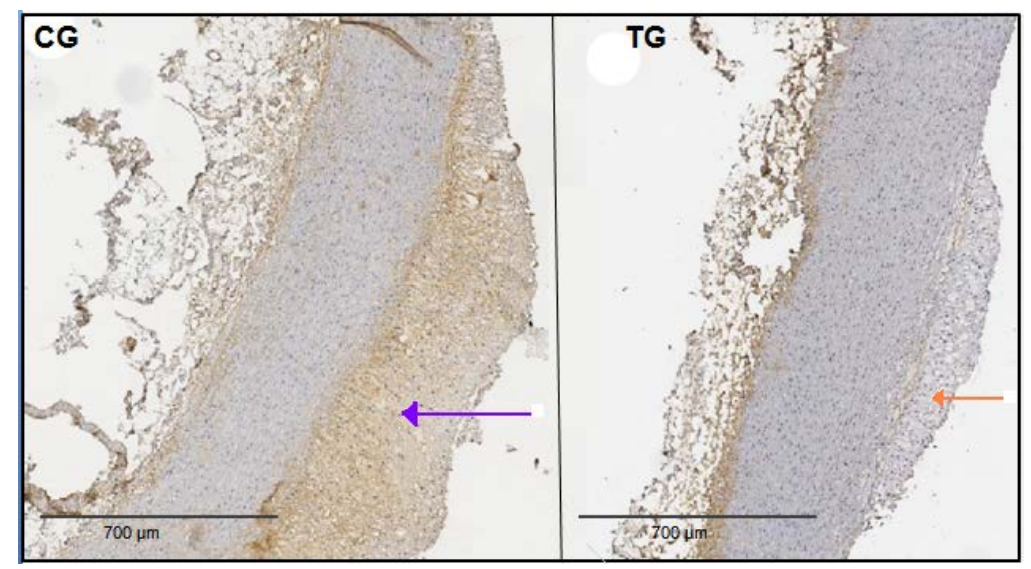

Figure 1. Photomicrograph of cross-section's detail of aorta in immunohistochemistry. In the left side, a sample of control group (CG) strongly marked with anti-MMP-9 antibody in the plaque (brown color, purple arrow), while treated group (TG) represented on the right side presented weak marking with antiMMP-9 antibody (orange arrow). Magnification, $\times 8$. 


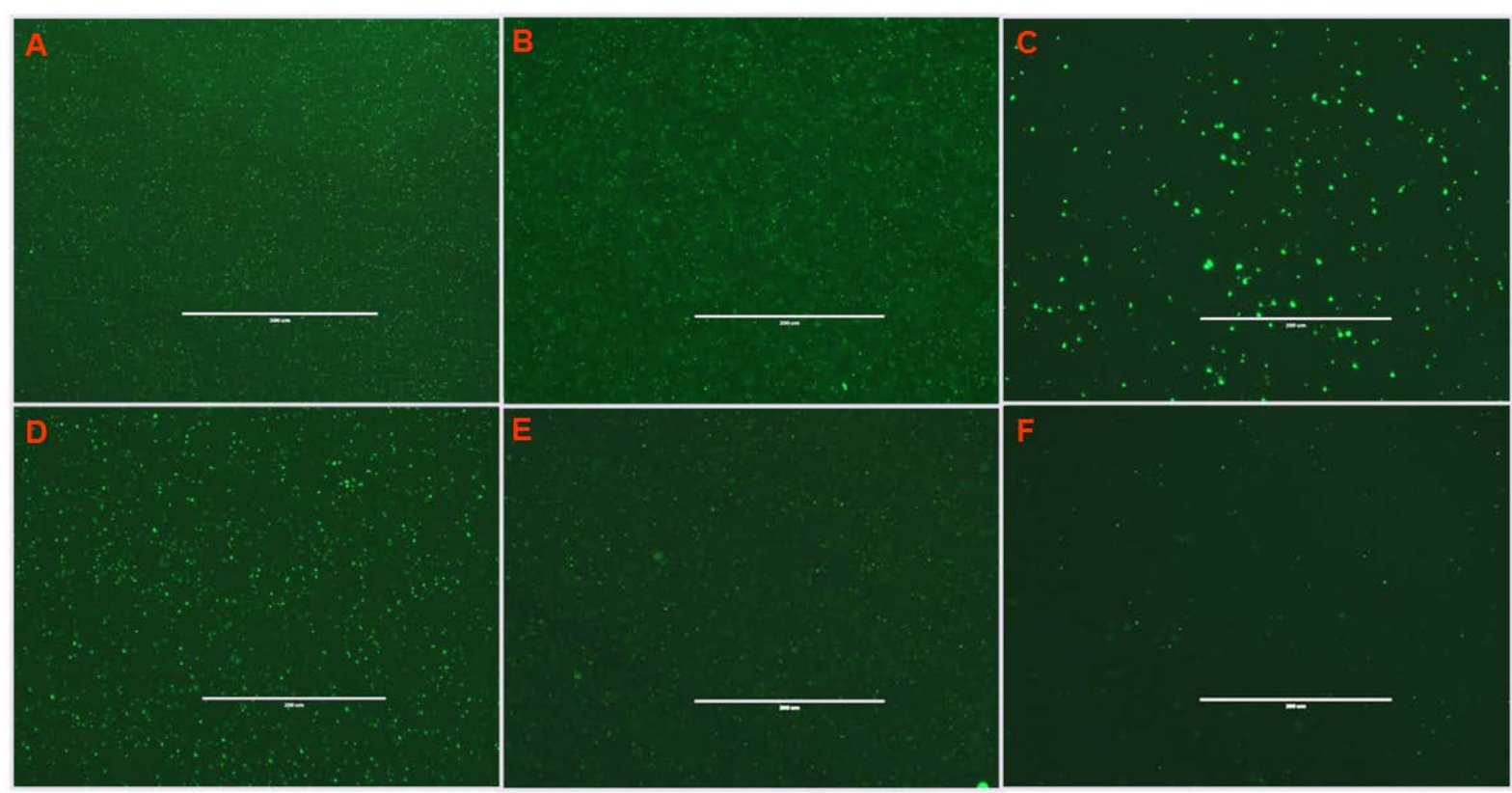

Figure 2. Immunofluorescence fields analyzed. Difference in the quantity of particles marked with anti-ox-LDL and Mp antibodies pre and post treatment. Control group (CG) presented high amount of particles marked with anti-ox-LDL antibody (A) as well as treated group (TG) before the treatment with PTCTS (B). After the treatment, TG demonstrated a significant reduction in particles marked with anti-ox-LDL antibody in serum (C). The same effect was noticed against antigens of mycoplasma. CG presented a high amount of particles marked with anti-Mp antibody (D) as well as treated group (TG) before the treatment with PTCTS (E). After the treatment, TG demonstrated a significant reduction in particles marked with anti-Mp antibody in serum (F). Magnification $\times 20$.

\subsection{Correlations}

We correlated the values obtained from immunohistochemistry with the ones from immunofluorescence in order to understand how the inflammatory process developed in the two different groups.

The results showed that in CG NF- $\kappa$ B correlated weakly with MMP-9 $(r=0.77 P=0.07)$ and negatively with particles marked with $\mathrm{Mp}$ in the serum $(\mathrm{r}=-0.71 \mathrm{P}=0.11)$. There was no other correlation in control group.

In the other hand, in group TG, NF- $\kappa$ B correlated negatively with MMP-9 $(r=-0.84 P=0.03)$ and weakly with ox-LDL in the plaque $(r=-0.78 P=0.06)$, there was weak correlations of MMP-9 with ox-LDL in the plaque $(\mathrm{r}=0.65 P=0.16)$ and of the ox-LDL present in the plaque with the ox-LDL in the serum $(\mathrm{r}=0.68 P=$ $0.14)$. IL- $1 \beta$ correlated weakly with both of the antigens marked in the serum: positively with ox-LDL $(r=0.67$ $P=0.14)$ and negatively with $\mathrm{Mp}(\mathrm{r}=-0.62 \mathrm{P}=0.18)$.

\section{Discussion}

Inflammatory response is a normal physiological reaction of the body to restore and maintain homeostasis [24]. Innate immune system mechanisms of defense are activated to kill and remove most of the harmful substances. The innate and the adaptive immune response, although often viewed as separated systems, are intertwined and affect each other [25].

PTCTS organic nanoparticles would work as exogenous anti-oxidant benign exosomes and the transialidase would detach mycoplasmas by removing sialic acid from their main sites and releasing them to act as ligand of the siglecs components family.

Mycoplasmas are among the few prokaryotes that can grow almost "symbiotically" and have a close interaction with mammalian host cells for long periods of time [26], these bacteria are able to synthesize lipoproteins as MALP-404, a large lipoprotein previously described by Wise's laboratory as P41. Derived from MALP-404, MALP-2, a macrophage activating lipopeptide of about 2kDa mol. (Figure 3), is responsible for the comparatively much higher activity of the mycoplasmal product [27] by inducing the response of cytokines, chemokines and prostaglandins by activated macrophage. 
Besides all the mycoplasma's effects when in human body, apparently they also exert both apoptotic and anti-apoptotic effects, respectively promoting internucleosomal DNA fragmentation, induction of a number of pro-inflammatory cytokines production and activation of $\mathrm{NF}-\kappa \mathrm{B}$, or by activation of resting murine and human lymphocytes, inducing their proliferation, on mammalian cells [28].

Several studies demonstrated that mycoplasmas can activate NF- $\kappa$ B through different pathways. Mycoplasma may be recognized by TLR2 and TLR6 [29] through MALP-2, leading to the activation of NF- $\kappa$ B and resulting in the synthesis of pro-inflammatory cytokines TNF- $\alpha$, IL-1 $\beta$ and IL-6 [30] (Figure 4).

NF- $\kappa$ B binding sites B are present in lots of cytokines genes, including TNF-a, IL-6 and IL-1 $\beta$ [31] [32].

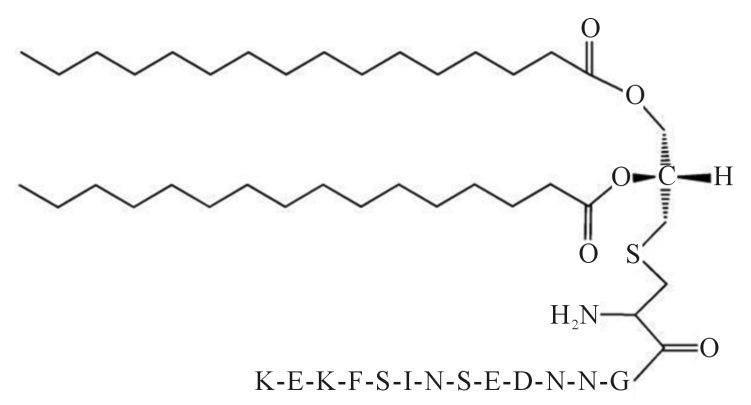

Figure 3. Structure of synthetic MALP-2.

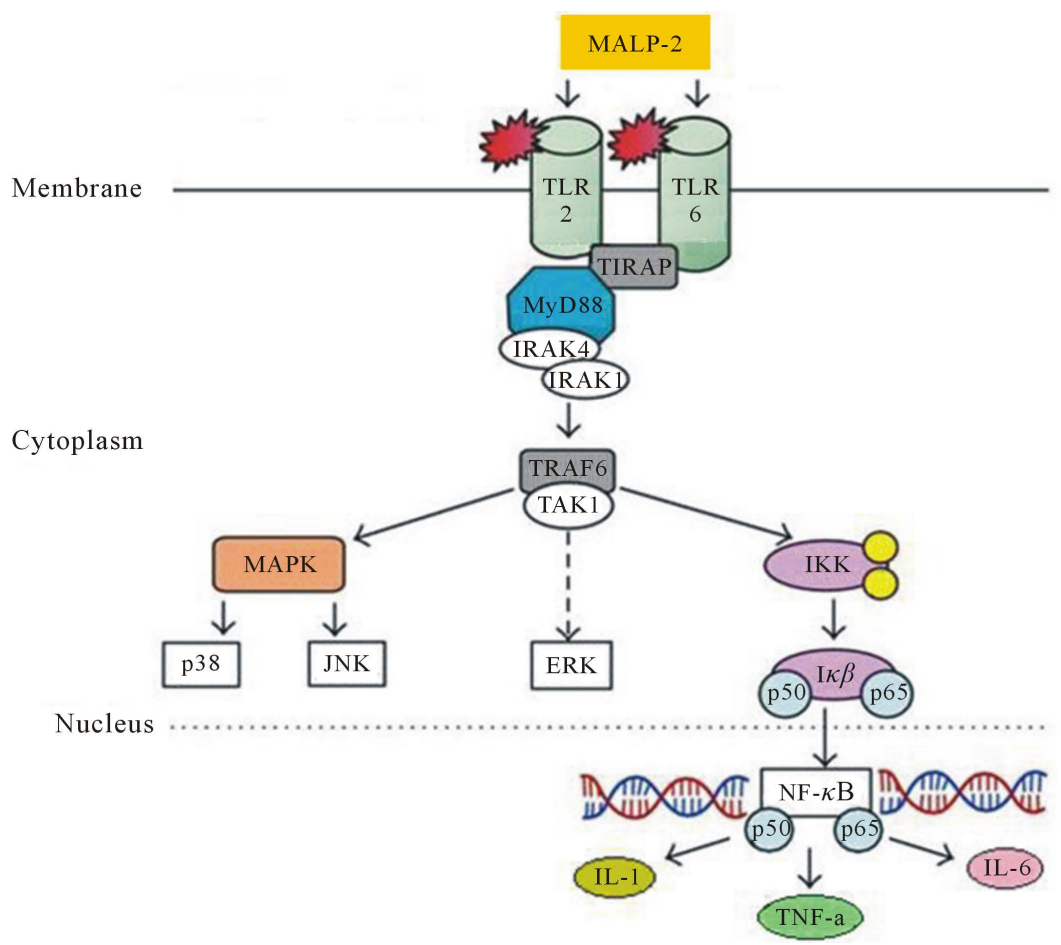

Figure 4. TLR-2, TLR-6, recognize MALP-2 from mycoplasma membrane, recruit adaptor protein MyD88 and activate common upstream activator (IRAK/TRAF6 and TAK1) of NF-B and MAPK. Activated NF- $\kappa$ B and MAPK translocate to the nucleus and bind to their motifs (NF- $\kappa \mathrm{B}, \mathrm{AP}-1)$ in the promoter of target genes (including early-response and inflammatory genes) and induce their transcription into mRNA which will ultimately lead to increased cytokine production. p38 MAPK also involved posttranscriptional regulation of pro-inflammatory genes by modulation of mRNA stability in the cytoplasm. (TLR: toll-like receptor, MyD88: myeloid differentiation primary response gene 88; IRAK: interleukin-1 receptor-associated kinase; TRAF6: TNF receptor associated factor 6; TAK1: TGF-beta activated kinase 1; ERK: extracellular signal-regulated kinase: JNK: c-Jun N-terminal kinase). 
Once PTCTS is administrated orally, we could notice its first actions in the blood, with significant reduction in the numbers of circulating microparticles containing antigens of ox-LDL and micoplasma.

Oral treatment with PTCTS did not decrease significantly the levels of NF- $\kappa$ B in the tissue, but once it reduced the presence of mycoplasma, the activation of NF- $\kappa$ B through MALP-2 pathway was also reduced. This decrease may have contributed to the lower levels of IL- $1 \beta$ in the tissue, represented by the negative correlation with Mp and positively with ox-LDL, both in the serum.

PTCTS also lead to a lower expression of MMP-9, demonstrated by the negative correlation of the collagenase with NF- $\kappa$ B.

The negative correlation of NK- $\kappa \mathrm{B}$ and ox-LDL in the plaque could mean that once the immune response is going back to its normal, the reduction of ox-LDL was still not visible in the tissue, but as soon as the immune response stabilize the treatment would present better effects in this site too. All these data suggest that a longer period of treatment with PTCTS and/or adjustments in its admixture could reduce the inflammation in the tissue to levels that belong to a normal, not an exacerbated immune response by reducing two of the most important agents that contribute to the development of atherosclerosis: ox-LDL and pathogenic microorganisms, Mycoplasma pneumoniae in this case; as well as act with the stabilization of the atheromatous plaque by reducing the presence of MMP-9 in the tissue.

These data suggest that PTCTS acts in the control the exacerbated inflammation and in the stabilization of the plaque.

\section{Conclusion}

Rabbits treated with oral PTCTS presented an improvement in the inflammatory response by reducing levels of ox-LDL, IL-1 $\beta$ and mycoplasma, as well as a better stabilization of the atheromatous plaque by reducing levels of MMP-9, avoiding plaque rupture, without causing mortality or toxicity.

\section{Funding}

This work was supported by FAPESP (Fundation that supports research in the State of São Paulo, grant number 2012/12656-5) and Zerbini Foundation.

\section{References}

[1] Ross, R. (1999) Atherosclerosis Is an Inflammatory Disease. American Heart Journal 138, S419-S420. http://dx.doi.org/10.1016/s0002-8703(99)70266-8

[2] Libby, P. (2002) Inflammation in Atherosclerosis. Nature, 420, 868-874. http://dx.doi.org/10.1038/nature01323

[3] Lusis, A.J. (2000) Atherosclerosis. Nature, 407, 233-241. http://dx.doi.org/10.1038/35025203

[4] Cybulsky, M.I., Iiyama, K., Li, H., Zhu, S., Chen, M., Iiyama, M., Davis, V., Gutierrez-Ramos, J.C., Connelly, P.W. and Milstone, D.S. (2001) A Major Role for VCAM-1, but Not ICAM-1, in Early Atherosclerosis. Journal of Clinical Investigation, 107, 1255-1262. http://dx.doi.org/10.1172/JCI11871

[5] Binder, C.J., Hartvigsen, K., Chang, M.K., Miller, M., Broid, D., Palinski, W., Curtiss, L.K., Corr, M. and Witztum, J.L. (2004) IL-5 Links Adaptative and Natural Immunity Specific for Epitopes of Oxidized LDL and Protects from Atherosclerosis. Journal of Clinical Investigation, 114, 427-437. http://dx.doi.org/10.1172/JCI200420479

[6] Brand, K., Eisele, T., Kreusel, U., Page, M., Page, S., Haas, M., Gerling, A., Kaltschmidt, C., Neumann, F.J., Mackman, N., Baeurele, P.A., Walli, A.K. and Neumeier, D. (1997) Dysregulation of Monocytic Nuclear Factor- $\kappa$ B by Oxidized Low-Density Lipoprotein. Arteriosclerosis, Thrombosis, and Vascular Biology, 17, 1901-1909. http://dx.doi.org/10.1161/01.ATV.17.10.1901

[7] Muller, J.R. and Siebenlist, U. (2003) Lymphotoxinbeta Receptor Induces Sequential Activation of Distinct NF- $\kappa$ B Factors via Separate Signaling Pathways. The Journal of Biological Chemistry, 278, 12006-12012. http://dx.doi.org/10.1074/jbc.M210768200

[8] Collins, T. and Cybulsky, M.I. (2001) NF- $\kappa$ B: Pivotal Mediator or Innocent Bystander in Atherogenesis? Journal of Clinical Investigation, 107, 255-264. http://dx.doi.org/10.1172/JCI10373

[9] Berliner, J.A., Territo, M.C., Sevanian, A., Ramin, S., Kim, J.A., Bamshad, B., Esterson, M. and Fogelman, A.M. (1990) Minimally Modified Low-Density Lipoprotein Stimulates Monocyte Endothelial Interactions. Journal of Clinical Investigation, 85, 1260-1266. http://dx.doi.org/10.1172/JCI114562

[10] Dechend, R., Maass, M., Gieffers, J., Dietz, R., Scheidereit, C., Leutz, A. and Gulba, D.C. (1999) Chlamydia Pneumo- 
niae Infection of Vascular Smooth Muscle and Endothelial Cells Activates NF- $\kappa$ B and Induces Tissue Factor and PAI1 Expression: A Potential Link to Accelerated Arteriosclerosis. Circulation, 100, 1369-1373. http://dx.doi.org/10.1161/01.CIR.100.13.1369

[11] Maia, I.L., Nicolau, J.C., Machado, M.N., et al. (2005) Prevalência de Chlamydia pneumoniaee Mycoplasma pneumoniae em diferentes formas de doença coronariana. Arquivos Brasileiros de Cardiologia, 92, 439-445.

[12] Winther, M.P.J., Kanters, E., Kraal, G. and Hofker, M.H. (2005) Nuclear Factor $\kappa$ B Signaling in Atherogenesis. Arteriosclerosis, Thrombosis, and Vascular Biology, 25, 904-914. http://dx.doi.org/10.1161/01.ATV.0000160340.72641.87

[13] Brach, M.A., Henschler, R., Mertelsmann, R.H. and Herrmann, F. (1991) Regulation of M-CSF Expression by M-CSF: Role of Protein Kinase C and Transcription Factor NF- $\kappa$ B. Pathobiology, 59, 284-288. http://dx.doi.org/10.1159/000163664

[14] Bond, M., Fabunmi, R.P., Baker, A.H. and Newby, A.C. (1998) Synergistic Upregulation of Metalloproteinase-9 by Growth Factors and Inflammatory Cytokines: An Absolute Requirement for Transcription Factor NF- $\kappa$ B. FEBS Letters, 435, 29-34. http://dx.doi.org/10.1016/S0014-5793(98)01034-5

[15] Galis, Z.S., Johnson, C., Godin, D., Magid, R., Shipley, J.M., Senior, R.M. and Ivan, E. (2002) Targeted Disruption of the Matrix Metalloproteinase-9 Gene Impairs Smooth Muscle Cell Migration and Geometrical Arterial Remodeling. Circulation Research, 91, 852-859. http://dx.doi.org/10.1161/01.RES.0000041036.86977.14

[16] Shah, K.P. and Galis, Z.S. (2001) Matrix Metalloproteinase Hypothesis of Plaque Rupture Players Keep Piling up but Questions Remain. Circulation, 104, 1878-1880.

[17] Packard, R.R.S. and Libby, P. (2008) Inflammation in Atherosclerosis: From Vascular Biology to Biomarker Discovery and Risk Prediction. Clinical Chemistry, 54, 24-38. http://dx.doi.org/10.1373/clinchem.2007.097360

[18] Roggerio, A., Sambiase, N.V., Palomino, S.A.P., Castro, M.A.P., Silva, E.S., Stolf, N.G. and Higuchi, M.L. (2013) Correlation of Bacterial Coinfection versus Matrix Metalloproteinase 9 and Tissue Inhibitor of Metalloproteinase 1 Expression in Aortic Aneurysm and Atherosclerosis. Annals of Vascular Surgery, 27, 964-971. http://dx.doi.org/10.1016/j.avsg.2013.02.012

[19] Higuchi, M.L., Reis, M.M., Sambiase, N.V., Palomino, S.A.P., Castelli, J.B., Gutierrez, O.S., Aiello, V.D. and Ramires, J.A.F. (2003) Co-infecção por Mycoplasma pneumoniae e Chlamydia pneumoniae em Placas Rotas associadas a Infarto Agudo do Miocárdio. Arquivos Brasileiros de Cardiologia, 81, 1-11.

[20] Assis, R.M., Higuchi, M.L., Reis, M.M., Palomino, S.A.P., Hirata, R.D.C. and Hirata, M.H. (2014) Involvement of TLR2 and TLR4, Chlamydophila pneumoniae and Mycoplasma pneumoniae in Adventitial Inflammation of Aortic Atherosclerotic Aneurysm. World Journal of Cardiovascular Diseases, 4, 14-22. http://dx.doi.org/10.4236/wjcd.2014.41004

[21] Ikegami, R.N., Kawakami, J.T., Abdalla, D.S.P., Santos, R.D., Filho, R.K., Ramires, J.A.F. and Higuchi, M.L. (2015) Infection and Microparticles May Cause Complication of Atherosclerotic Plaques. Journal of Diabetes \& Metabolism, 6, 1-4. http://dx.doi.org/10.4172/2155-6156.1000537

[22] Higuchi, M.L., Santos, M.H.H., Fagundes, R.Q., Palomino, S.A.P. and Reis, M.M. (2011) Trans-Sialidase from Trypanosoma cruzi: Na Anti-Atherosclerotic Drug. Proceedings of the Keystone Symposia on Molecular and Cellular Biology—Drugs from Bugs: The Anti-Inflammatory Drugs of Tomorrow, Snowbird Resort, 3-7 April 2011, 66.

[23] Santos, M.H.H., Ikegami, R.N., Reis, M.M., Fagundes, R.Q. and Higuchi, M.L. (2007) A New Therapeutic Proposal for Lipid Lowering Treatment: Association of Transialidase and Anti-Oxidant Elements. Na Experimental Study in Rabbits. Proceedings of the XVI International Symposium on Drugs Affecting Lipid Metabolism—DALM, New York, 4-7 October 2007, 474.

[24] Greenberg, S. and Grinstein, S. (2002) Phagocytosis and Innate Immunity. Current Opinion in Immunology, 14, 136145. http://dx.doi.org/10.1016/S0952-7915(01)00309-0

[25] Hansson, G.K., Libby, P., Schonbeck, U. and Yan, Z.Q. (2002) Innate and Adaptive Immunity in the Pathogenesis of Atherosclerosis. Circulation Research, 91, 281-291. http://dx.doi.org/10.1161/01.RES.0000029784.15893.10

[26] Iyama, K., Zhang, S. and Lo, S.C. (2001) Effects of Mycoplasmal LAMPs on Receptor Responses to Steroid Hormones in Mammalian Cells. Current Microbiology, 43, 163-169. http://dx.doi.org/10.1007/s002840010281

[27] Wise, K.S., Kim, M.F., Theiss, P.M. and Lo, S.C. (1993) A Family of Strain-Variant Surface Lipoproteins of Mycoplasma fermentans. Infection and Immunity, 61, 3327-3333.

[28] Pucci, B., Kasten, M. and Giordano, A. (2000) Cell Cycle and Apoptosis. Neoplasia, 2, 291-299. http://dx.doi.org/10.1038/sj.neo.7900101

[29] Muneta, Y., Uenishi, H., Kikuma, R., Yoshihara, K., Shimoji, Y., Yamamoto, R., Hamashina, N., Yokomizo, Y. and Mori, Y. (2003) Porcine TLR2 and TLR6: Identification and Their Involvement in Mycoplasma hyopneumoniae Infection. Journal of Interferon \& Cytokine Research, 23, 583-590. http://dx.doi.org/10.1089/107999003322485080 
[30] You, X., Yimou, W., Zeng, Y., Deng, Z., Qiu, H. and Minjun, Y. (2008) Mycoplasma genitalium-Derived LipidAssociated Membrane Proteins Induce Activation of MAPKs, NF-kB and AP-1 in THP-1 Cells. FEMS Immunology \& Medical Microbiology, 52, 228-236. http://dx.doi.org/10.1111/j.1574-695X.2007.00366.x

[31] May, M.J. and Ghosh, S. (1998) Signal Transduction through NF- $\kappa$ B. Immunology Today, 19, 80-88. http://dx.doi.org/10.1016/S0167-5699(97)01197-3

[32] Siebenlist, U., Franzoso, G. and Brown, K. (1994) Structure, Regulation and Function of NF- $\kappa$ B. Annual Review of Cell Biology, 10, 405-455. http://dx.doi.org/10.1146/annurev.cb.10.110194.002201 